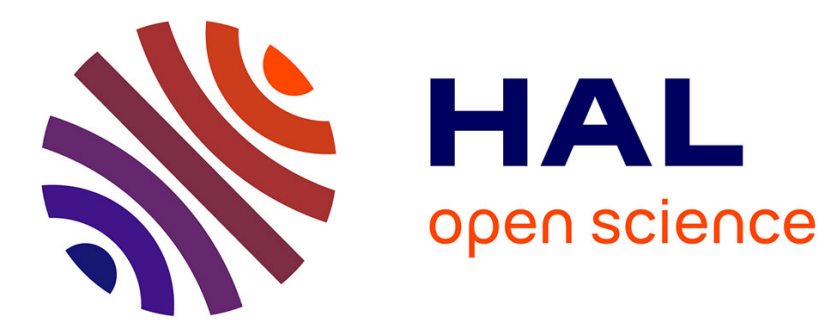

\title{
Use of the modified Arcan fixture to study the strength of bonded assemblies for automotive applications
}

\author{
Leonardo Alfonso, Claudiu Badulescu, Nicolas Carrère
}

\section{To cite this version:}

Leonardo Alfonso, Claudiu Badulescu, Nicolas Carrère. Use of the modified Arcan fixture to study the strength of bonded assemblies for automotive applications. International Journal of Adhesion and Adhesives, 2018, 80, pp.104-114. 10.1016/j.ijadhadh.2017.09.014 . hal-01701138

\section{HAL Id: hal-01701138 \\ https://hal-ensta-bretagne.archives-ouvertes.fr/hal-01701138}

Submitted on 17 Jun 2021

HAL is a multi-disciplinary open access archive for the deposit and dissemination of scientific research documents, whether they are published or not. The documents may come from teaching and research institutions in France or abroad, or from public or private research centers.
L'archive ouverte pluridisciplinaire HAL, est destinée au dépôt et à la diffusion de documents scientifiques de niveau recherche, publiés ou non, émanant des établissements d'enseignement et de recherche français ou étrangers, des laboratoires publics ou privés. 


\title{
Use of the modified Arcan fixture to study the strength of bonded assemblies
}

\section{for automotive applications}

\author{
L. ALFONSO ${ }^{1 *}$, C. BADULESCU ${ }^{1}$, N. CARRERE ${ }^{1}$ \\ 1 : Institut de Recherche Dupuy de Lôme (IRDL), ENSTA-Bretagne, 2 rue François Verny, 29806 Brest, Cedex 09, France \\ *Corresponding author: \\ Leonardo ALFONSO \\ E-mail:leonardo. Alfonso@ensta-bretagne.org
}

\begin{abstract}
Adhesive joints are being increasingly used as a good solution to assemble primary structures of metallic and composite materials. Hence, the analysis of the behaviour of adhesively-bonded assemblies under mixed loadings is a critical issue for industry. This article discusses the use of the modified Arcan device to identify the strength of adhesively-bonded metal/metal and metal/composite assemblies. Different assemblies have been tested and their failure envelopes have been determined. Moreover, analyses have also been made of the influence of some crucial parameters on the behaviour of the as semblies in the study such as the composite surface state, the fabric orientation, the humidity and the presence of grease.
\end{abstract}

Keywor ds: Adhesively-bonded assemblies, Modified Arcan test, Failure mode, and Failure envelope.

\section{INTRODUCTION}

Nowadays, adhesive joints are being increasingly used to assemble primary structures in almost all engineering applications, e.g. automotive [1], aerospace, medical prosthetics, alternative energy generation, civil engineering [2] and sports devices. This technique provides many interesting advantages for industry. These include the joining of dissimilar materials such as aluminium, steel, titanium, thermoplastic and thermoset composite with different configurations (glass or carbon fibre, ply orientations, textile/laminate/unidirectional, etc.).Conventional assembling methods such as riveting or bolting require the drilling of holes which induces stress 
concentration on the composite plate and can lead to an early failure of the composite [3][4]. Adhesive joints provide a more uniform stress distribution with an efficient load transfer [5][6]. Hence, adhesively-bonded joints represent a major advance for the use of composite materials in various industrial applications.

The design of such bonded multi-material structures requires the determination of (i) the global stiffness, and (ii) the failure load along with the associated failure mode. These parameters, which mostly depend on the loading, the nature of the substrates, the adhesive, and the interfaces, lead to various adhesive or cohesive types of failure (see Figure 1).

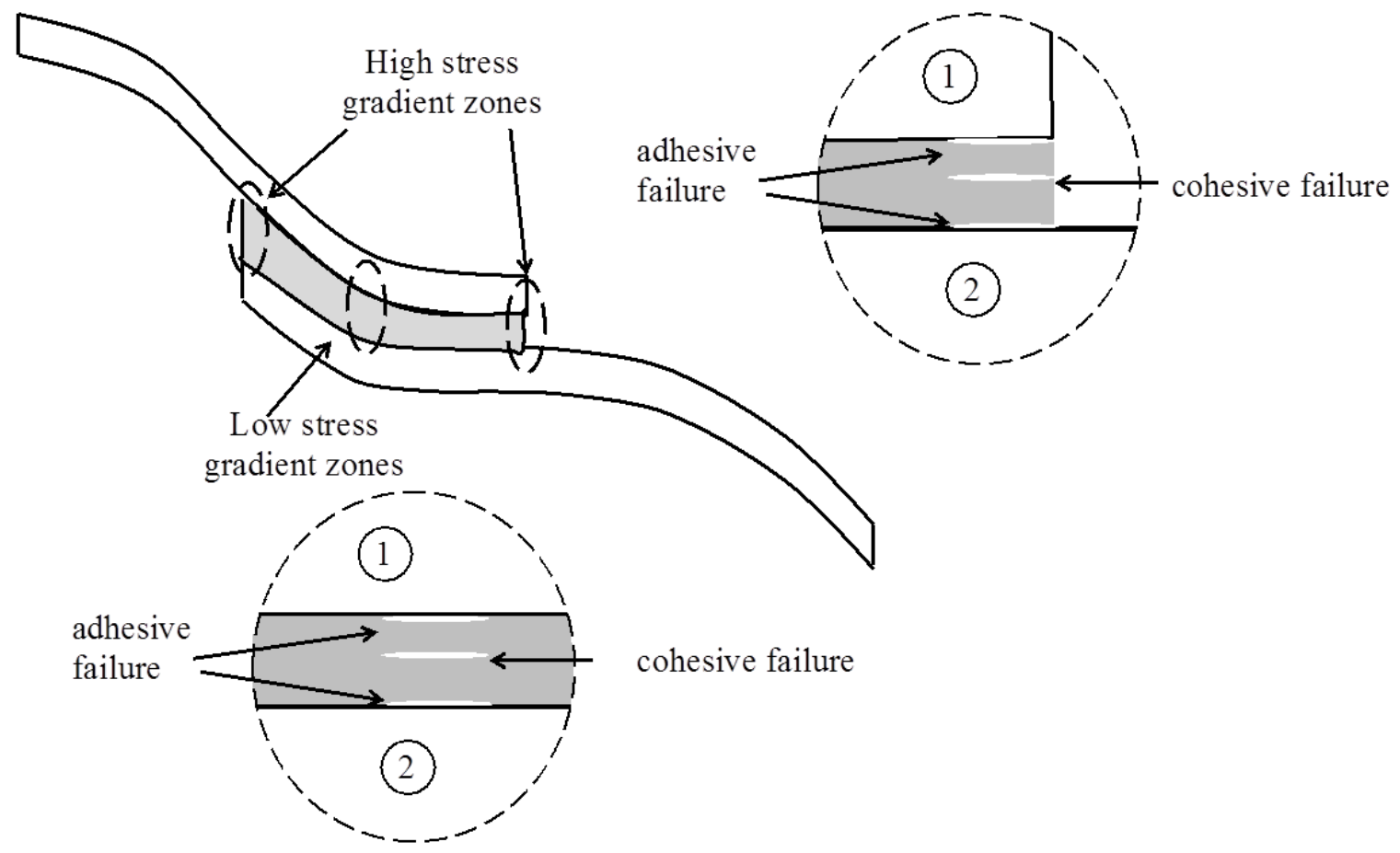

Figure 1 : Representation of different failure modes and their locations in adhesively-bonded joints. Definition of the high and low stress gradient zones.

Tests on bulk specimens permit the elastic properties of the adhesive to be determined [7][8]. Some standard tests (Thick Adherent Shear Test [9] or Single Lap Specimens [10]) or nonstandard tests (such as the Scarf specimen test [11]) can be used to study the failure of 
adhesively-bonded specimens. However, most of these tests are not suitable for composite substrates (TAST or Scarf specimen tests are performed on very thick specimens in order to be representative of an industrial composite application). Moreover, due to the high presence of edge effects on such types of experiments [12], complex tri-axial stresses are located in the so-called "high stress gradient zones" (As shown in Figure 1), which lead to the onset and propagation of premature cracks that will pilot the global response of the joint. Since the presence of these high stress gradient zones and their influence on the strength of the joint are greatly influenced by the local geometry of the joint, the global geometry of the structure, the state of the adherend, the type of loading, etc., it turns out to be quite difficult to extrapolate the results obtained on such traditional specimens to other configurations.

In order to develop a method that can be applied to a large number of bonded assemblies (for example in terms of geometry and loading) and be able to study the adhesion issue (interactions between the adhesive, the adherend and the interface) without the influence of external parameters such as edge effects, first of all, it is necessary to study the behaviour of bonded joints in a well-controlled stress state. This methodology ensures an accurate characterisation of the joint behaviour that only depends on the interactions between the adherends, the adhesive and the interface. Eventually, it will be necessary to include the influence of edge effects, the local geometry and the stress concentration over the global response in order to characterise the behaviour, the strength and the type of failure of the adhesive joint in the final application. This paper thus focuses on the first case; however, as discussed in the last section of this manuscript, it will be necessary to develop a new methodology in order to take into account the multiaxial problem and the influence of external parameters such as the local geometry. 
The study of the type of failure in a well-controlled stress state was performed by means of the modified Arcan device proposed by J.Y. Cognard [13], which has been widely used in diverse experimental and numerical studies of the behaviour of adhesives and bonded assemblies [15][16][17]. This experimental test is based on the works of Arcan [14].In order to reduce the influence of the edge effects (avoiding high stress gradient zones), the substrates were manufactured with special "beaks" all around the bonded surface of the substrates of the Arcan device [18]. This specific geometry drastically reduces the stress concentrations and permits a quasi-uniform stress state to be created (out-of-plane for tensile loadings and in-plane for shear loadings) with a maximum value at the centre of the adhesive joint [18]. This specimen type has been used to investigate the behaviour of adhesive under different loading configurations (cyclic [19], creep [20], load temperatures [21]) and also to study the strength of composites [22]. The study of the adhesion between adhesive and composites has been previously attempted. However, the results still remain at a very early stage [23].

The aim of the present paper is to study the behaviour up to failure of adhesively-bonded aluminium/composite and aluminium/metal assemblies used in automotive applications under a quasi-homogeneous stress state (representative of the low stress gradient zone shown in Figure 1). Therefore, the stiffness of the adhesive and the mode of failure of such specimens subjected to multi-axial loadings have been determined. The paper presents the experimental procedure, the analysis of results concerning the strength of the adhesives and the assemblies of the study. The effect of different parameters such as humidity, fabric orientation and presence of grease has also been also investigated in this study. 


\section{EXPERIMENTAL PROCEDURE}

The methodology proposed is based on the modified Arcan fixture to generate mixed tensile/shear loadings and compression/shear loadings on the assemblies. The load is generated by means of a universal tensile machine with a maximum load of $100 \mathrm{kN}$. The main characteristics of the procedure implemented in this study are detailed below.

\subsection{Experimental set-up}

The modified Arcan device consists of two half-moon shaped pieces made of high stiffness steel. A bonded specimen is gripped in these two pieces (which are above and below) as shown in Figure 2-b. Finally, the Arcan apparatus (the two half-moon shaped pieces and the bonded specimen) is placed in a universal tensile machine (see Figure 2-a). The type of loading is chosen thanks to the angle between the axis of the tensile machine and the normal plane of the bonding surface (angle $\gamma$ between the $v$-axis and the $z$-axis in Figure 2-c). For the needs of the current study, four different loading types were tested:

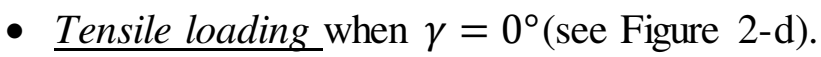

- Pure shear loading when $\gamma=90^{\circ}$ (see Figure 2-e).

- Proportional tensile/shear loading when $\gamma=45^{\circ}$ (see Figure 2-f).

- Proportional compression/shear loading when $\gamma<135^{\circ}$ (see Figure 2-g). 


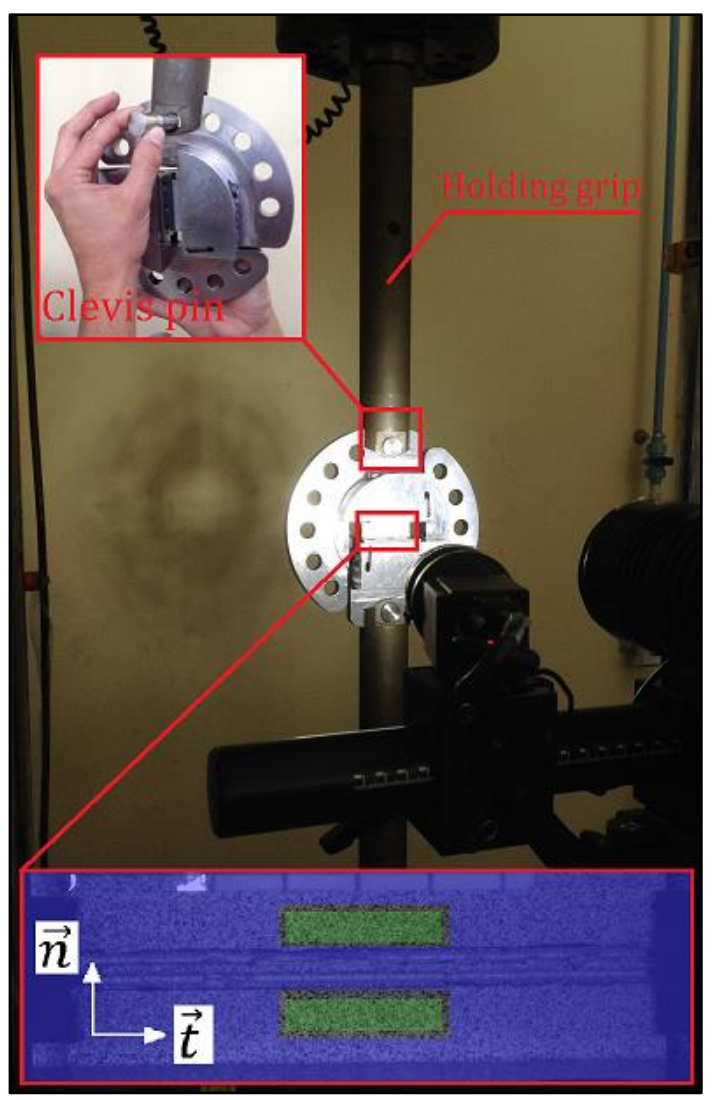

(a) Experimental set-up

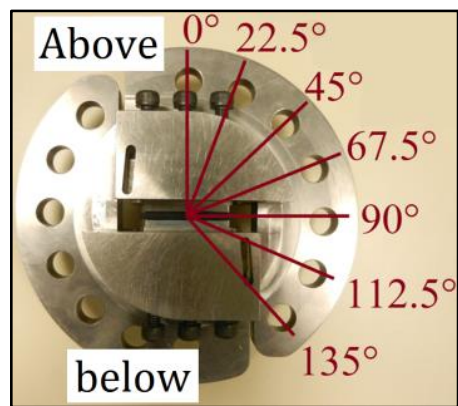

(b) Orientation angles

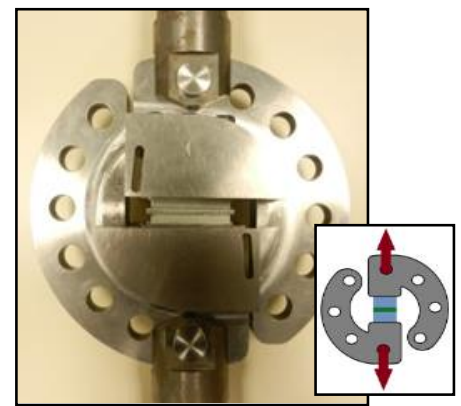

(d) "Tensile" load $\left(\gamma=0^{\circ}\right)$

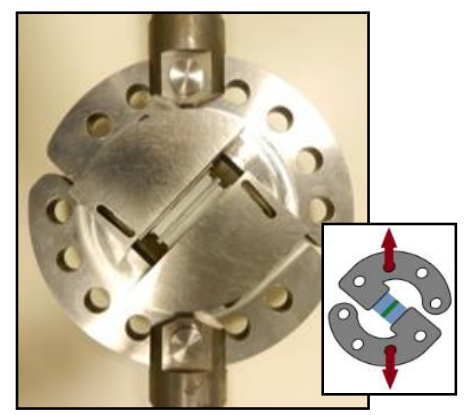

(f) Tensile/shear load $\left(\gamma<45^{\circ}\right)$

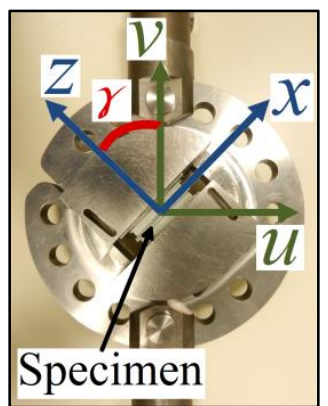

(c) Specimen coordinate system

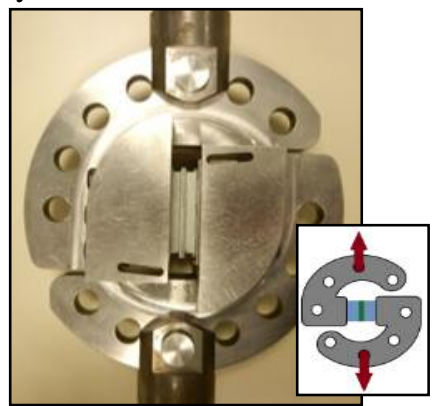

(e) Shear load $\left(\gamma=90^{\circ}\right)$

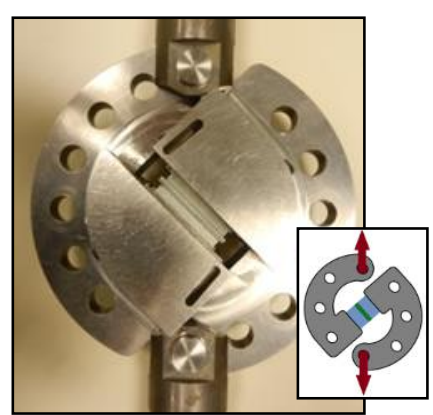

(g) Compression/shearload $\left(\gamma<135^{\circ}\right)$

Figure 2: Mounting of the modified Arcan fixture and different configurations to generate the various loading types.

As explained in the introduction, this paper focuses on the investigation of the strength of the adhesive and of the competition between adhesive and cohesive failure in bonded metal/metal or metal/composite specimens. Figure 3 shows the two specimen configurations tested in this study. The specimen presented in Figure 3-a was used to study the strength of the adhesive; this specimen was composed of two aluminium substrates adhesively bonded. It is obvious that the adhesive layer defines the middle plane of the specimen. The thickness of the adhesive layer was equal to $0.4 \mathrm{~mm}$. This type of specimen will be noted as "the adhesive specimen" in the 
following. Figure 3-b presents the specimen configuration to study the interaction between the adhesive and the cohesive failure of composite/metal and metal/metal assemblies; a thin plate (composite or metal) was inserted between the two substrates, creating two adhesive layers of $0.2 \mathrm{~mm}$ on each side of the plate. This was decided so as to maintain the total adhesive layer thickness at $0.4 \mathrm{~mm}$. For this second configuration, the composite or metal plate defines the plane of symmetry of the specimen.

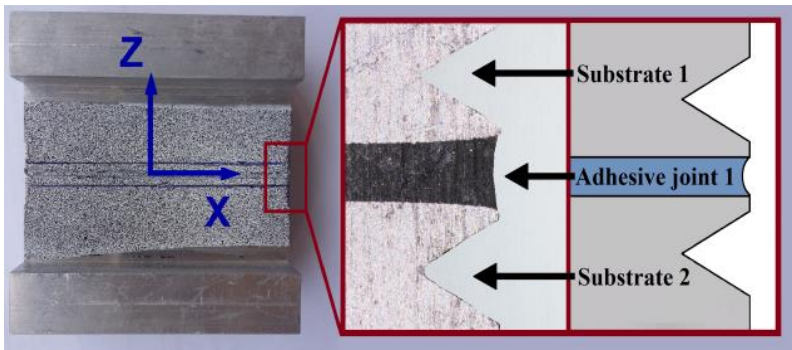

(a)

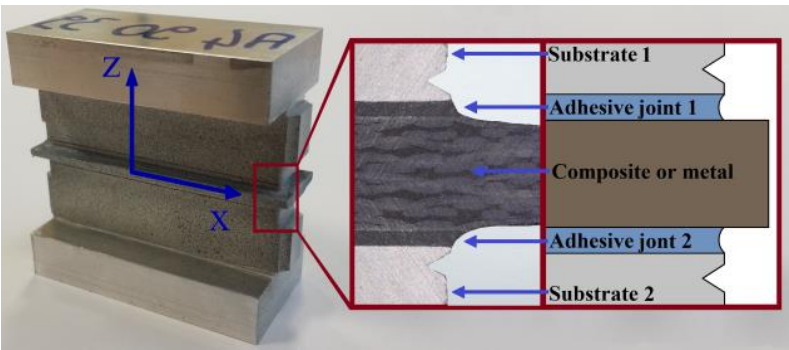

(b)

Figure 3: Specimen used to study the strength of the adhesive (a) (noted as "the adhesive specimen" in the following) and specimen used to study the composite/metal and the metal/metal strength (b).

The post-treatment process was accomplished using the Aramis ${ }^{\circledR}$ Digital Image Correlation Software version 6.3.1. developed by GOM [24]. The DIC system used here is able to measure the relative displacement of the Arcan substrates with a minimum resolution of $1 \mu m$. The procedure thus required a speckled pattern applied on one side of the substrates. Two10x3mm regions defined on the upper and lower substrates were used to measure the displacements (see Figure 2-a). These regions were always at a distance of 2-mm from the bonded joint for all the specimens tested. This allowed a correct comparison between the results. Note that the relative displacement of the two substrates was composed of the normal displacement"ND" (which is the displacement along the $\overrightarrow{\mathrm{n}}$ direction) and the tangential displacement "TD" (which is the displacement along the $\vec{t}$ direction). The load applied to the specimen was recorded thanks to the machine load-cell. The ultimate stress was defined as the load applied by the tensile machine 
before failure divided by the bonded area $(S=50 \times 9.5 \mathrm{~mm})$. This assumption was not entirely satisfactory since it did not take into account either the non-linear behaviour of the adhesive up to failure or the non-homogeneous 3D stress distribution over the bonded surface [18]. However, it was acceptable for this study, since the main objective was the determination of the failure envelope and not the study of the damage behaviour after failure. Some authors have determined a correction coefficient through elastic numerical simulations in order to estimate the real value of the stress on the adhesive joint [19]. A better estimation could be achieved by using inverse identification via FEM as proposed in [22].

Finally, the surfaces of the adhesive layer after fracture were studied by means of a Keyence ${ }^{\circledR}$ digital microscope with a maximal zoom of x500.

\subsection{Preparation of the Arcan specimens}

The surfaces of the substrates to bond were sandpapered manually with a grain size of $115 \mu m$ to guarantee a homogeneous roughness. Then, all remaining dust particles were removed by means of $99 \%$ pure acetone and the surfaces were blow-dried. In the case of aluminium/composite or aluminium/metal assemblies, the surfaces of the composite or the metal plates were only cleaned up with acetone and blow-dried. The adhesive was then immediately applied over the surfaces to bond and the specimens were placed in the thermal chamber. The curing cycle was 25 minutes of controlled heating up to $200^{\circ} \mathrm{C}$ plus 20 minutes of stabilised temperature. This cycle was preferred according to the datasheet of the adhesives and the requirements of the automotive production chain. 
The thickness of the adhesive was controlled by means of two"spacers" placed on each side of the substrates as shown in Figure 4-a [19]. The substrates were maintained in this position during the curing process by two screws screwed with a torque screwdriver set at $2.5 \mathrm{Nm}$. Eventually, the spacers were removed from the specimens just before the tests.

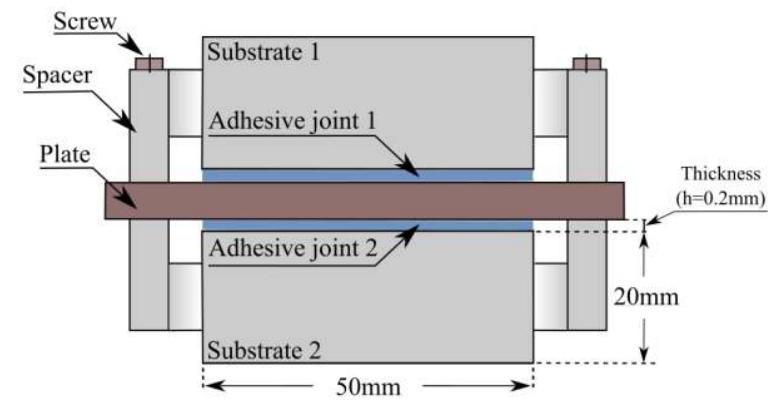

(a)

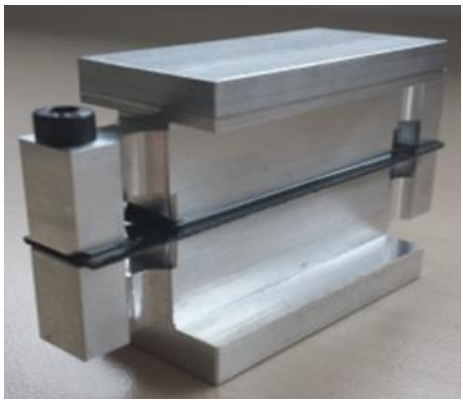

(b)

Figure 4: Bonding system geometry (a).Photo of a real specimen with a composite plate before polymerisation (b).

\subsection{Materials}

The Arcan substrates were manufactured using an aluminium alloy (A12022). Two crash optimised single-compound epoxy adhesives were studied: the Sikapower 498 and the Betamate1822. A large range of dissimilar composite and metal materials summarised in Table 1 and Table 2 respectively were used to generate the necessary assemblies. For the sake of simplicity, in the following sections, the specimens noted as BM1822 and SP498 correspond to "adhesive specimens" bonded with Betamate1822 and Sikapower 498 respectively. A specimen noted as BM1822/composite or SP498/composite corresponds to a bonded aluminium/composite specimen bonded with Betamate1822 and Sikapower 498 respectively. Similarly, a specimen noted BM1822/metal or SP498/metal corresponds to a bonded aluminium/metal specimen. The set of assemblies tested is summarised in Table 3 . 


\begin{tabular}{|l|l|l|l|l|l|l|}
\hline Index & Material & Morphology & $\begin{array}{l}\text { Fibre content } \\
\text { volume }\end{array}$ & Density & $\begin{array}{l}\text { Glass Transition } \\
\text { temperature }\left({ }^{\circ} \mathbf{C}\right)\end{array}$ & $\begin{array}{l}\text { Thickness } \\
(\mathbf{m m})\end{array}$ \\
\hline PA66 & $\begin{array}{l}\text { PA66 HF } \\
\text { consolidated } \\
\text { laminate }\end{array}$ & $\begin{array}{l}\text { 5 layers, 8H } \\
\text { Satin balanced }\end{array}$ & $\begin{array}{l}50 \% \text { glass } \\
\text { fibre }\end{array}$ & $\begin{array}{l}1.87 \\
\left(\mathrm{~g} / \mathrm{cm}^{3}\right)\end{array}$ & 69 & 2.04 \\
\hline Prepreg & Carbon prepreg & Twill 2x2 & $\begin{array}{l}50 \% \text { carbon } \\
\text { fibre }\end{array}$ & $\begin{array}{l}195 \\
\left(\mathrm{~g} / \mathrm{m}^{2}\right)^{*}\end{array}$ & $\begin{array}{l}115-120 \text { after } \\
90 \mathrm{~min}\end{array}$ & 2 \\
\hline $\begin{array}{l}\text { SMC- } \\
\text { Chopped }\end{array}$ & $\begin{array}{l}\text { Vinylester SMC } \\
\text { chopped glass }\end{array}$ & $\begin{array}{l}\text { Chopped glass } \\
\text { fibre }(25 \mathrm{~mm})\end{array}$ & $\begin{array}{l}50 \% \text { glass } \\
\text { fibre }\end{array}$ & $\begin{array}{l}1.96 \\
\left(\mathrm{~g} / \mathrm{cm}^{3}\right)\end{array}$ & 145 & 2.2 \\
\hline $\begin{array}{l}\text { SMC- } \\
\text { fabric }\end{array}$ & $\begin{array}{l}\text { Vinylester SMC } \\
\text { fabric glass }\end{array}$ & $\begin{array}{l}\text { 2 layers, Non } \\
\text { crimp fabric }\end{array}$ & $\begin{array}{l}50 \% \text { glass } \\
\text { fibre }\end{array}$ & $\begin{array}{l}1.61 \\
\left(\mathrm{~g} / \mathrm{cm}^{3}\right)\end{array}$ & 145 & 1.8 \\
\hline
\end{tabular}

Table 1: Composite materials used in this study.

\begin{tabular}{|c|c|c|c|c|c|c|c|}
\hline Index & Material & $\begin{array}{l}\text { Content } \\
(\%)\end{array}$ & Density & Rigidity & $\begin{array}{l}\text { Tensile } \\
\text { yield } \\
\text { strength }\end{array}$ & $\begin{array}{l}\text { Ultimate } \\
\text { tensile } \\
\text { strength }\end{array}$ & $\begin{array}{l}\text { Thickness } \\
\text { (mm) }\end{array}$ \\
\hline AL5182 & $\begin{array}{l}\text { Aluminium } \\
5182\end{array}$ & $\begin{array}{lc}\mathrm{Al} & 95.2 \\
\mathrm{Mg} & 4.5 \\
\mathrm{Mn} 0.35\end{array}$ & $\begin{array}{l}2.65 \\
\mathrm{~g} / \mathrm{cm}^{3}\end{array}$ & $\begin{aligned} E & =70 \mathrm{GPa} \\
\vartheta & =0.33\end{aligned}$ & $140 \mathrm{MPa}$ & $400 \mathrm{MPa}$ & 2 \\
\hline Steel22MnB5 & $\begin{array}{l}\text { Steel } \\
\text { 22MnB5 }\end{array}$ & $\begin{array}{lc}\text { C } & 0.25 \\
\text { Mn } 1.4 \\
\text { Si } \quad 0.35 \\
\end{array}$ & $\begin{array}{l}7.8 \\
\mathrm{~g} / \mathrm{cm}^{3}\end{array}$ & $\begin{array}{l}E=210 G P a \\
\vartheta=0.3\end{array}$ & $300 \mathrm{MPa}$ & $500 \mathrm{MPa}$ & 2 \\
\hline AL2022 & $\begin{array}{l}\text { Aluminium } \\
2022 \\
\text { (substrate) }\end{array}$ & $\begin{array}{l}\text { A193 } \\
\text { Cu5 } \\
\text { Mg } 0.5\end{array}$ & $\begin{array}{l}2,78 \\
\mathrm{~g} / \mathrm{cm}^{3}\end{array}$ & $\begin{array}{c}E=73 \mathrm{GPa} \\
\vartheta=0.33\end{array}$ & $280 \mathrm{MPa}$ & $480 \mathrm{MPa}$ & -- \\
\hline
\end{tabular}

Table 2: Metal materials used in this study.

\begin{tabular}{|c|c|c|c|c|c|}
\hline Index & Substrate 1 & Adhesive joint 1 & Plate & Adhesive joint 2 & Substrate 2 \\
\hline \multicolumn{6}{|l|}{ Adhesive assemblies: } \\
\hline BM1822 & AL2022 & BM1822 & -- & -- & AL2022 \\
\hline SP498 & AL2022 & SP498 & -- & -- & AL2022 \\
\hline \multicolumn{6}{|c|}{ Aluminium/composite assemblies: } \\
\hline BM 1822/PA66 & AL2022 & BM1822 & PA66 & BM1822 & AL2022 \\
\hline BM 1822/Prepreg & AL2022 & BM1822 & Prepreg & BM 1822 & AL2022 \\
\hline BM 1822/SMC-Chopped & AL2022 & BM 1822 & SMC-Chopped & BM1822 & AL2022 \\
\hline BM1822/SMC-fabric & AL2022 & BM1822 & SMC-fabric & BM1822 & AL2022 \\
\hline SP498/PA66 & AL2022 & SP498 & PA66 & SP498 & AL2022 \\
\hline SP498/Prepreg & AL2022 & SP498 & Prepreg & SP498 & AL2022 \\
\hline SP498/SMC-Chopped & AL2022 & SP498 & SMC-Chopped & SP498 & AL2022 \\
\hline SP498/SMC-fabric & AL2022 & SP498 & SMC-fabric & SP498 & AL2022 \\
\hline \multicolumn{6}{|c|}{ Aluminium/metal assemblies: } \\
\hline BM1822/AL5182 & AL2022 & BM 1822 & AL5182 & BM1822 & AL2022 \\
\hline BM1822/Steel22MnB5 & AL2022 & BM1822 & Steel22MnB5 & BM 1822 & AL2022 \\
\hline SP498/ AL5182 & AL2022 & SP498 & AL5182 & SP498 & AL2022 \\
\hline SP498/ Steel22MnB5 & AL2022 & SP498 & Steel22MnB5 & SP498 & AL2022 \\
\hline
\end{tabular}

Table 3: Set of tested assemblies. 


\section{EXPERIMENTAL RESULTS}

Monotonic tests were performed under displacement control at a rate of $0.5 \mathrm{~mm} / \mathrm{min}$ for all the assemblies presented in the previous section. The tests were carried out under standard laboratory conditions (approximately 40\% air humidity and $25^{\circ} \mathrm{C}$ ). In the following sessions, the denomination of the failure modes is based on the ASTM D-5573 technical standard [25].

\subsection{Adhesive specimens}

The first campaign focused on the investigation of the strength of the two adhesives of the study. Figure 5 shows the failure envelopes of the BM1822 and the SP498 adhesives under four types of loading: tensile $\left(\gamma=0^{\circ}\right)$, shear/tensile $\left(\gamma=45^{\circ}\right)$, shear $\left(\gamma=90^{\circ}\right)$ and compression/shear $(\gamma=$ $135^{\circ}$ ). Two continuous trend lines have been plotted as a guide in the analysis of the following results. The plotted ultimate stress corresponds to the load applied before failure divided by the bonded area. Two tests per type of loading were performed and a very low dispersion of the ultimate stress was observed between each pair. The type of failure of both adhesives was always cohesive as shown in Figure 6.

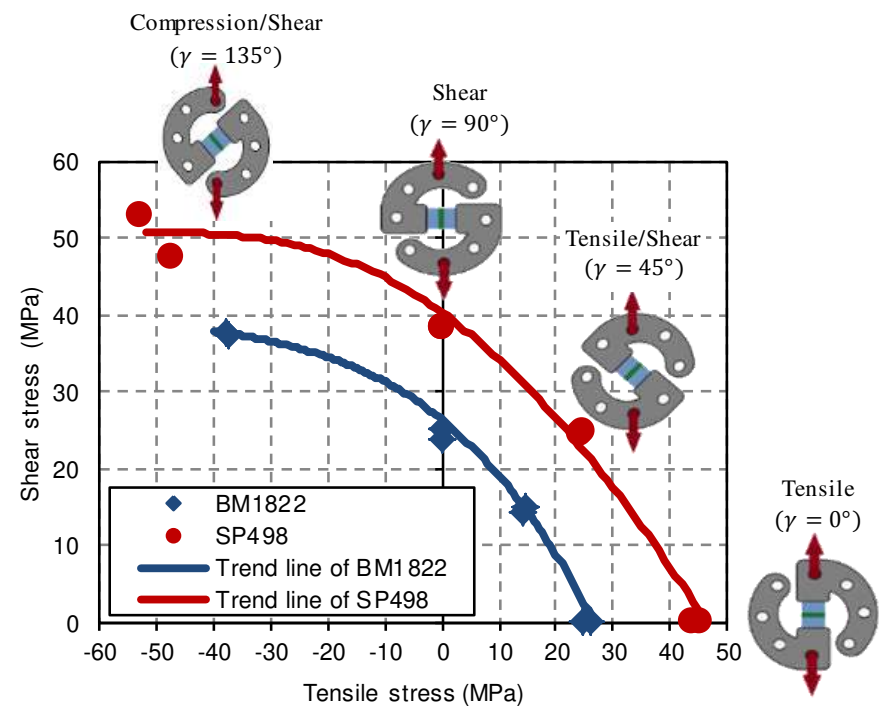

Figure 5: Failure envelopes of the BM1822 and the SP498 adhesives. 

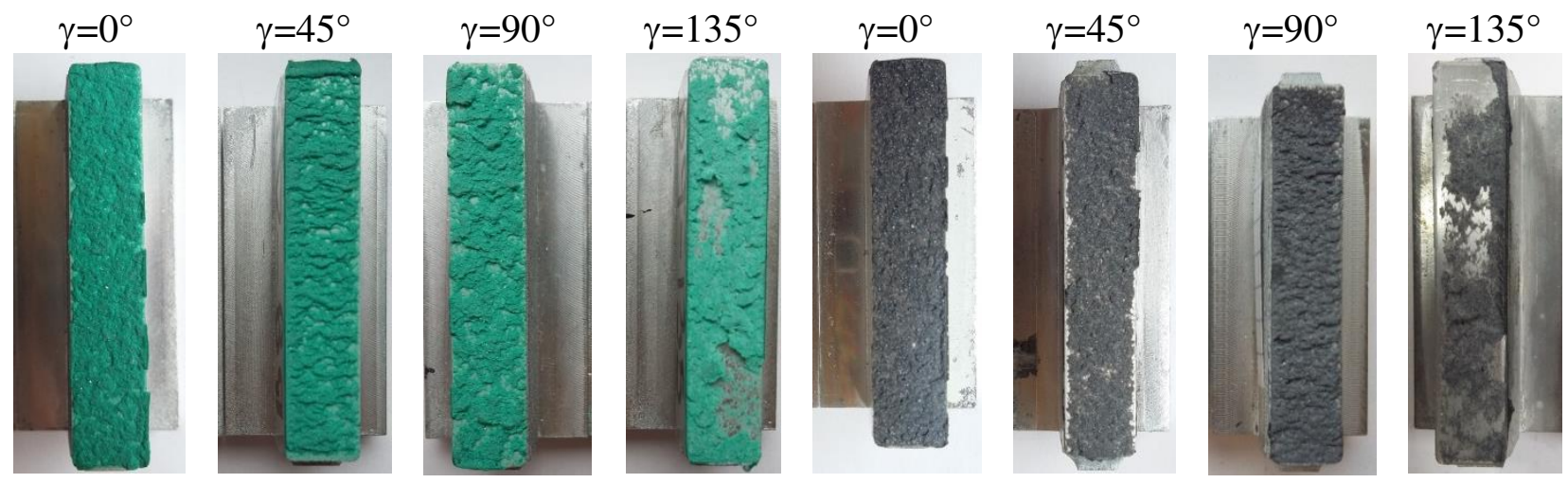

(a)

(b)

Figure 6: Cohesive failure modes for the BM1822 adhesive (a) and the SP498 adhesive (b).

The load-displacement curves of the adhesives subjected to tensile and shear loadings $\left(\gamma=0^{\circ}, 90^{\circ}\right)$ are presented in Figure 7. As can be seen, the behaviour of adhesive specimens is quite reproducible since the experimental curves have a low scattering and even overlapping. This repeatability is ensured by a rigorous checking of several parameters during the bonding procedure and the use of substrates with "beaks", as proposed in [18][26]. It is important to say that a similar conclusion was also observed for the rest of the assemblies tested in this study. Therefore, only two specimens per configuration (orientation and assembly) were necessary to validate the experimental results obtained by means of the Arcan device. On the other hand, Figure 7 also shows that both adhesives present an "elastic" regime followed by a large nonlinear regime. This reveals a great deformation of both adhesives under shear and tensile loadings, which is an important aspect in crash applications. Similarly, both adhesives present a different behaviour under tensile and shear loadings, which is due principally to the hydrostatic dependence of the adhesives. 


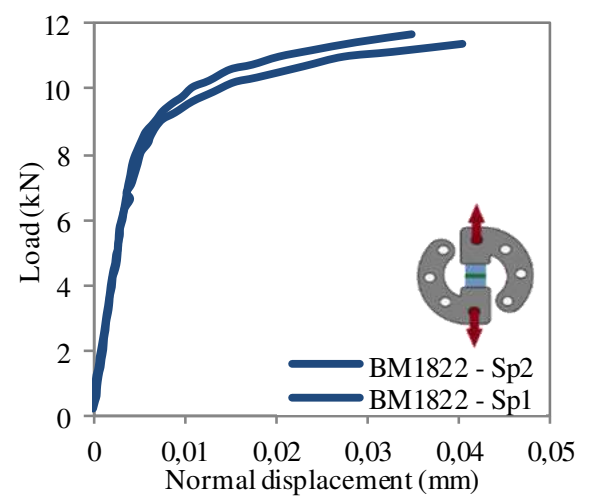

Tensile loading

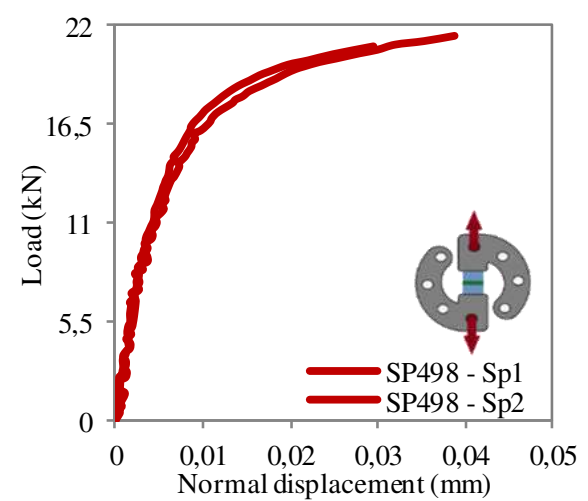

Tensile loading

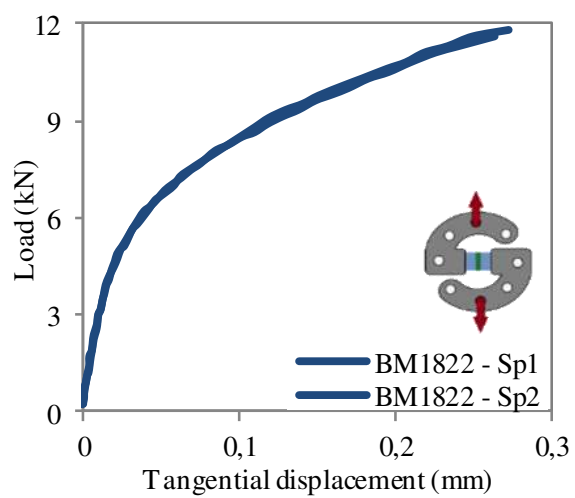

Shear loading

(a)

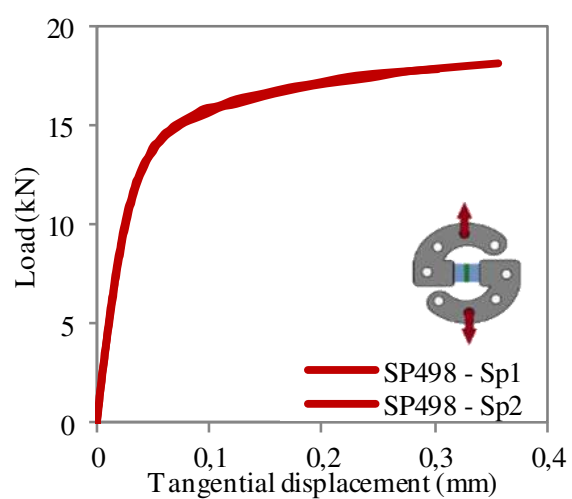

Shear loading

(b)

Figure 7: Load-displacement curves of the BM1822 (a) and SP498 adhesive (b).

\subsection{Strength and failure mode of composite/metal assemblies}

\subsubsection{Basic specimen configurations}

In order to determine the failure envelopes of the eight adhesive bonding aluminium/composite assemblies presented in Table 3, an experimental campaign was performed under four principal loadings: tensile, tensile/shear, shear and compression/shear (see Section2.1). The basic automotive bonding procedure was followed (see Section 2.2).

In the case of SMC Chopped and SMC Fabric assemblies, the fracture was always due to the delamination of the composite (see Figure 8-a-b). Hence, the out-of-plane strength of the SMC 
composites determines the strength of the assembly. It is worth mentioning that BM1822/SMC (Chopped or Fabric) specimens present a failure envelope close to and even a little higher than the failure envelope of the BM1822 adhesive. Since the thickness was $0.2 \mathrm{~mm}$ for the composite assemblies and $0.4 \mathrm{~mm}$ for the adhesive specimens, this could explain why the composite specimens have higher strength compared to the adhesive specimens. In fact, it has already been shown that thinner adhesive joints lead to higher adhesive strain rates and consequently to higher failure loads [27][28]. On the contrary, the failure envelopes of SP498/SMC (Chopped or Fabric) assemblies are lower than those of the SP498 adhesive.

Under tensile/shear loadings, shear loadings and compression/shear loadings, the BM1822/Prepreg assemblies and SP498/Prepreg assemblies exhibit a thin-layer cohesive failure (see Figure 8-c). On the other hand, under tensile loadings, the assemblies present a light-fibretear failure with a large zone of cohesive failure in the case of BM1822/Prepreg assemblies, and a complete delamination of the composite for SP498/Prepreg assemblies. This aspect suggests that the composite is the weakest link under tensile loadings and its failure load is close to the strength of the BM1822 adhesive.

In the case of BM1822/PA66 and SP498/PA66 assemblies, the failure surface was always adhesive. The failure load of the BM1822/PA66 assembly was close to that obtained with BM1822 specimens. It suggests that the strength of the adhesive/composite interface is close to that of the BM1822 adhesive. On the other hand, the strength of the SP498/PA66 assembly was lower than those of the SP498 specimens. The presence of adhesive fractures under any type of loadings implies a poor adhesive compatibility between the polyamide $6 / 6$ thermoplastic resin (composite) and the epoxy resin (adhesives). This aspect is more obvious for the SP498/PA66 assemblies because of the significant difference between the failure envelopes. 


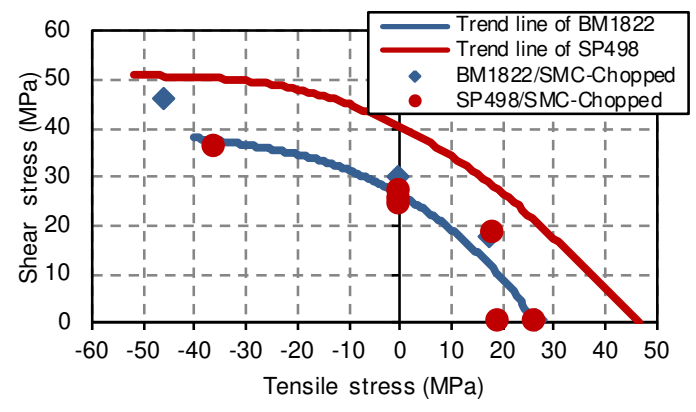

Failure envelope

(a) Aluminium/SMC-Chopped assembly

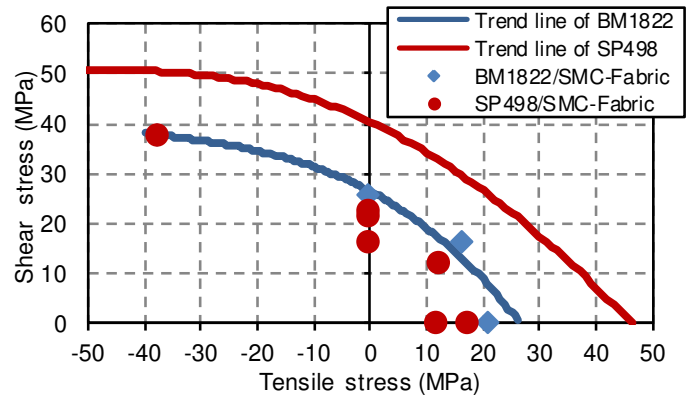

Failure envelope

(b) Aluminium/SMC-Fabric assembly

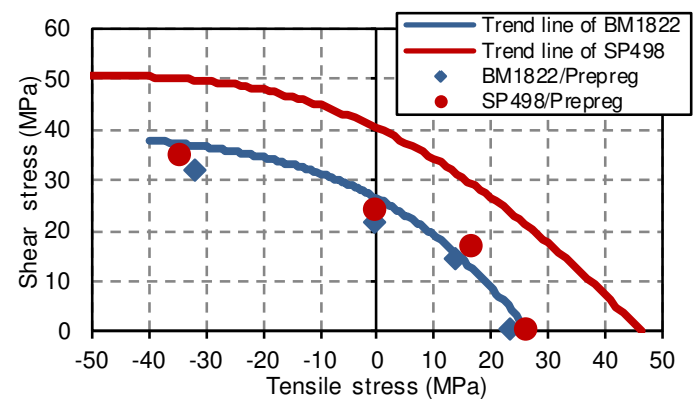

Failure envelope

(c) Aluminium/Prepreg assembly

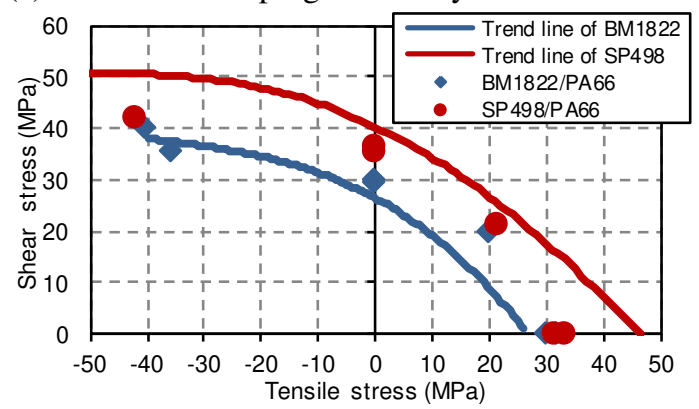

Failure envelope

(d) Aluminium/PA66 assembly

Figure 8: Failure envelopes and failure modes of the adhesively-bonded aluminium/composite assemblies tested in

this study. Assemblies subjected to four types of loading: tensile, shear/tensile, shear and compression/shear.

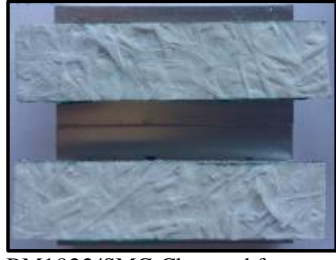

BM1822/SMC-Chopped fracture

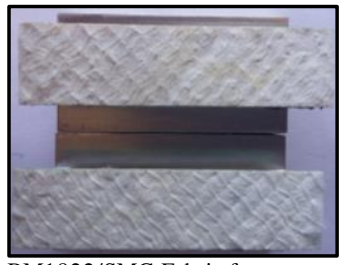

BM1822/SMC-Fabric fracture

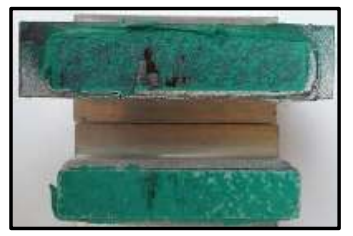

BM1 822/Prepreg fracture for

$\gamma=0^{\circ}$

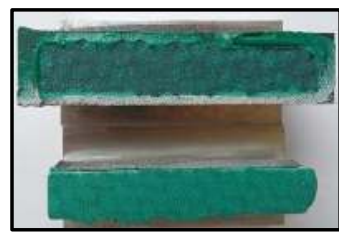

BM1822/Prepreg fracture for $\gamma=45^{\circ} ; 90^{\circ}$ and $135^{\circ}$

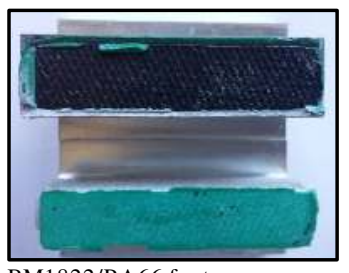

BM1822/PA66 fracture

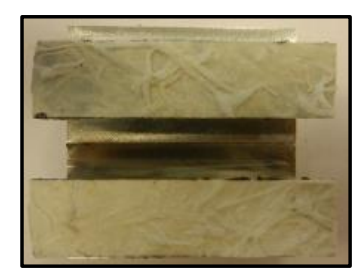

SP498/SMC-Chopped fracture

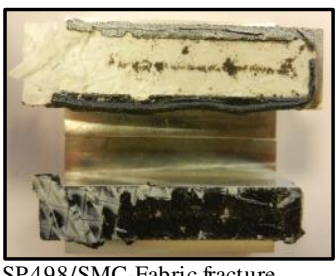

SP498/SMC-Fabric fracture

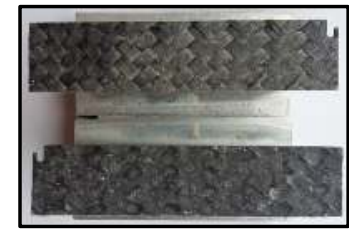

SP 498/Prepreg fracture for

$\gamma=0^{\circ}$

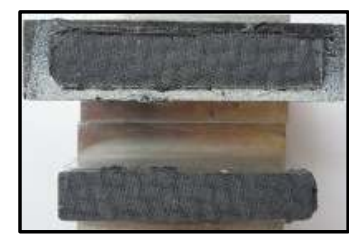

SP498/Prepreg fracture for $\gamma=45^{\circ} ; 90^{\circ}$ and $135^{\circ}$

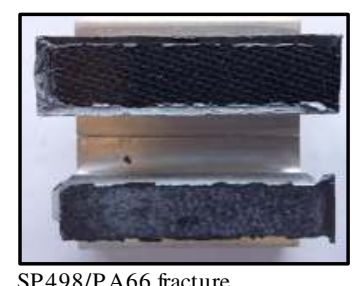

SP498/PA66 fracture 


\subsubsection{Influence of the fabric orientation over the strength of bonded composite}

assemblies

In order to determine the influence of the fabric orientation over the strength of adhesively bonded metal/composite assemblies, a second campaign was performed. The assemblies analysed were the SP498/PA66 and the BM1822/PA66; the orientations of the outer ply were $0^{\circ}, 45^{\circ}$ and $90^{\circ}$.Figure 9 presents the failure envelopes of the assemblies studied. We notice for both of them that the fabric orientation has a minor effect on the overall response of the assembly (very low discrepancy).

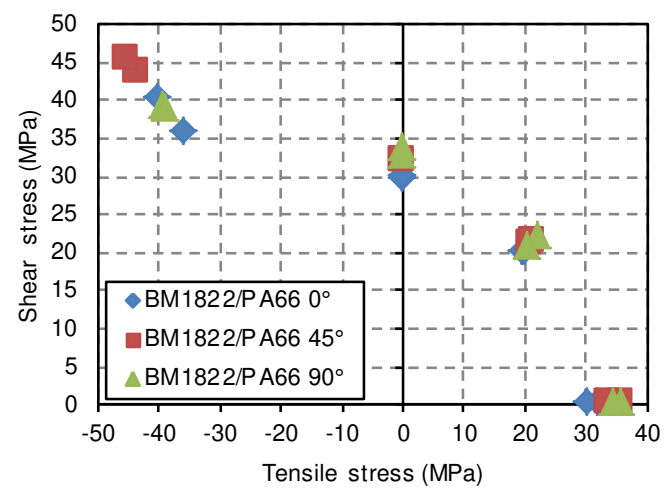

(a)

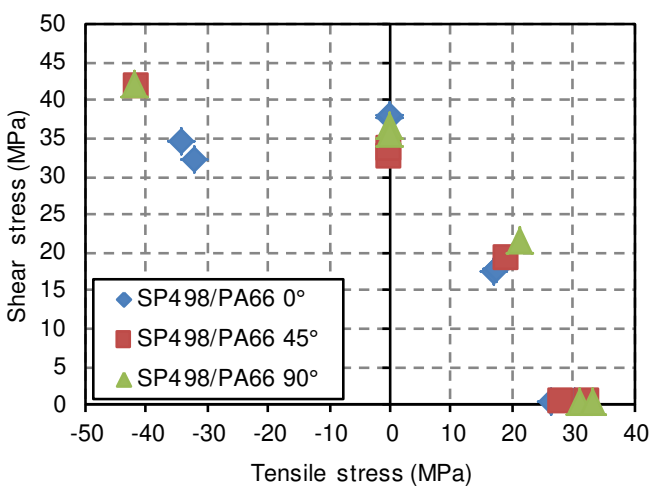

(b)

Figure 9: Failure envelopes of BM1822/PA66 specimens (a) and SP498/PA66 specimens (b) for different fabric orientations.

For all configurations and for both adhesives, the fracture was almost always adhesive (see Figure 10-a). However, when BM1822/PA66 assemblies with a fabric orientation of $45^{\circ}$ were subjected to tensile/shear loadings $\left(\gamma=45^{\circ}\right)$, the failure was cohesive (see Figure 10-b). In this particular case, the failure load of the assemblies was close to the failure load of the adhesive (BM1822). Therefore, at this phase angle, an interaction between the two failure modes takes place. It is also obvious that due to the morphology of the composite ( $8 \mathrm{H}$ satin), the behaviour of the assembly was orthotropic. It means that the stiffness is different for a $45^{\circ}$ orientation as compared to a $0^{\circ}$ orientation. These aspects could explain the different failure mode obtained for BM1822/PA66 assemblies. 


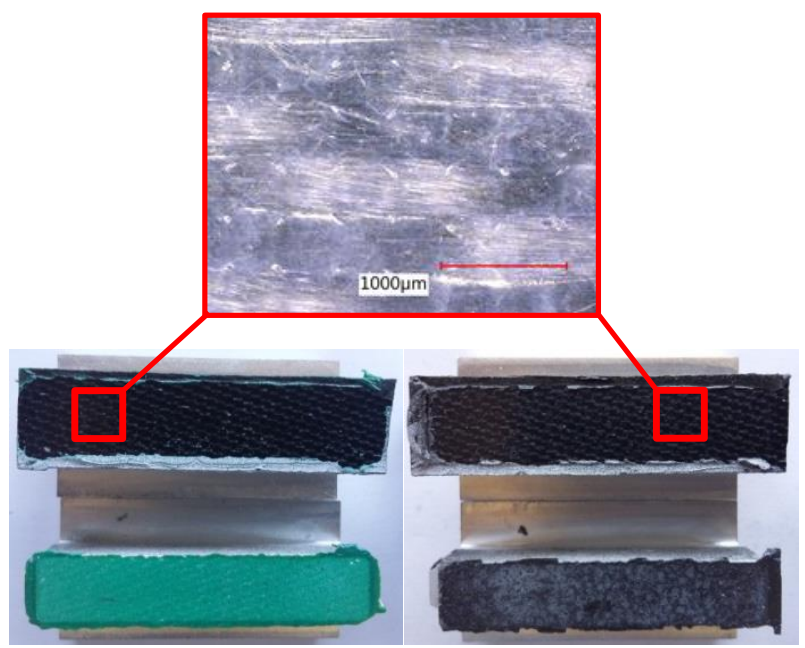

(a)

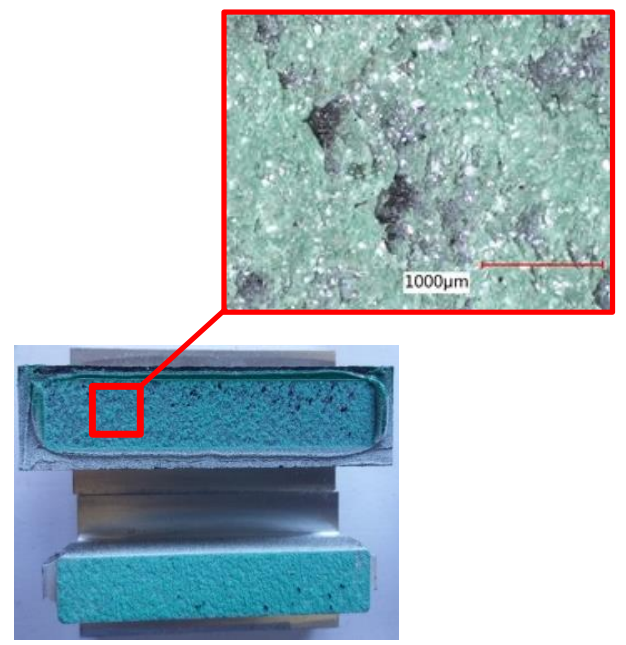

(b)

Figure 10: Type of fracture observed in relation to the fabric orientation. Adhesive failure for BM1822/PA66 assemblies (left) and SP498/PA66 assemblies (right) (a).Cohesive failure for BM1822/PA66 assemblies with a fabric orientation of $45^{\circ}$ and subjected to tensile/shear loadings (b).

\subsubsection{Influence of the surface state of the composite.}

The metal/PA66 assemblies bonded with the basic procedure presented adhesive failures (see Figure 8). In order to ensure a cohesive fracture with a higher failure load for composite assemblies, the composite surfaces were manually sanded with four progressive levels of sanding (see Figure 11-a):

P1. Virgin state without sanding: The composite surface is only cleaned up with acetone.

P2. Soft manual sanding: The objective was to homogenise the surface of the composite. The sandpaper used had a granulation size of $115 \mu m$.

P3. Intermediate manual sanding: The fibres were exposed and the resin had been removed. The sandpaper used had a granulation size of $530 \mu \mathrm{m}$. Under this configuration, the adhesive would stick directly over the fibres.

P4. Aggressive manual sanding: The outer weaves of the composite were strongly sanded and no piece of resin was observed. The sandpaper used had a granulation size of $530 \mu \mathrm{m}$. 
The specimens were subjected to shear Arcan loadings. Figure 11-b shows the registered loaddisplacement curves of the four surface states for a BM1822/PA66 assembly. All states presented similar behaviour. However, P3 and P4 levels exhibited a larger non-linear regime and a higher failure load (about 10\%). It is worth mentioning that the strength of the P4 state was slightly lower than that of the P3. Exposing the fibre of the composite improved the adhesion with the adhesive. However, an aggressive sanding could have led to a weakening of the in-plane mechanical properties of the composite because the outer fibres were cut and consequently the strength of the outer weave was reduced.

The failure mode was also affected by the surface state of the composite. P1 and P2 levels presented adhesive failures, while P3 and P4 presented cohesive failures. This means that the ultimate strength of the adhesive was achieved, generating a failure of the assembly by a fracture at the adhesive joint.

A similar campaign of manual sanding was performed on BM1822/Prepreg and SP498/Prepreg assemblies. In this case only P1 and P3 levels were applied over the surface of the composite (see Figure 11-c-d). The results also showed an improvement of the mechanical properties of the assemblies with a higher failure load and a bigger non-linear regimen. This aspect was more noticeable for SP498/Prepreg assemblies. Similarly, the failure modes changed from thin-layer cohesive fractures to more classic cohesive fractures with an aspect similar to those for "adhesive specimens" and with a failure load near the strength of the adhesives (see Figure 5). It is worth noting that assemblies with SMC composites were not tested because the failure in a virgin state (P1) always occurred by delamination of the composite plate (see Figure 8-a-b). 


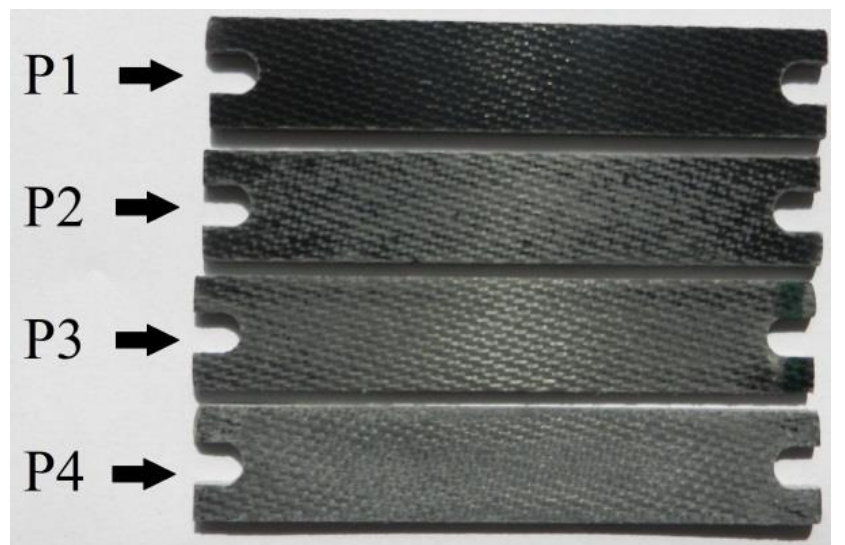

(a)

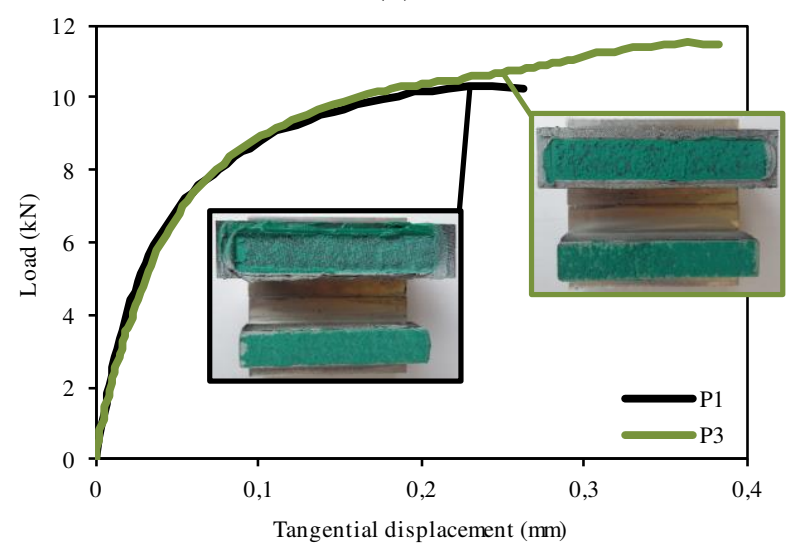

(c)

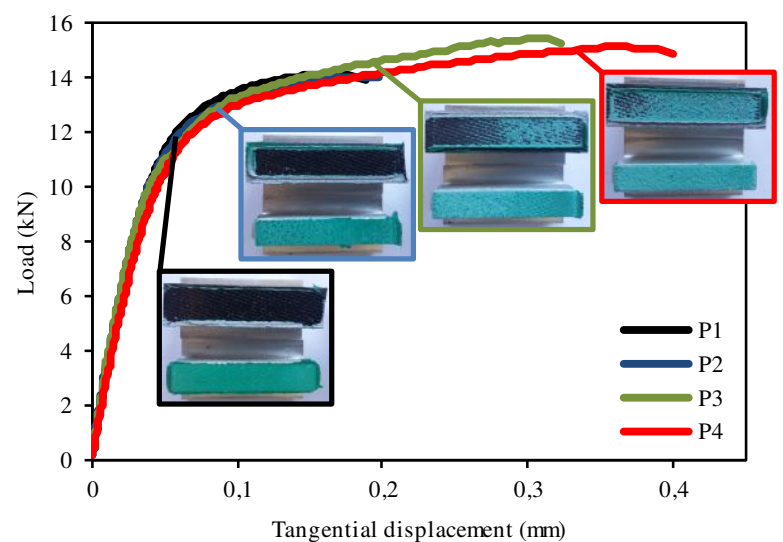

(b)

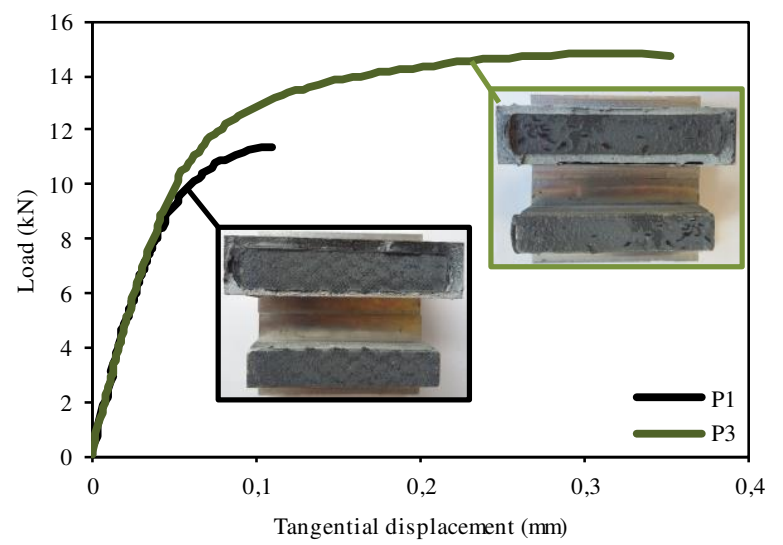

(d)

Figure 11: Influence of manual sanding on the failure load and the failure mode. Different levels of manual sanding tested (a). Load-displacement curves of Arcan shear test of BM1822/PA66 assemblies (b), BM1822/Prepreg assemblies (c) and SP498/Prepreg assemblies (d).

\subsubsection{Influence of the humidity.}

It is well known that the mechanical properties of thermoplastic composites and adhesives can be greatly affected by the absorption of humidity [29][30]. Indeed, humidity could lead to premature failures in bonded thermoplastic assemblies. In order to identify the behaviour of PA66 assemblies in humid environments representative of the service life of the car, shear Arcan tests were performed using BM1822/PA66 specimens conditioned at two different humidity levels: two specimens without humidity (RH0) and two others with $70 \%$ air humidity (RH70). The objective was to determine which element of the assembly (composite, adhesive or interface) was 
mainly affected by humidity. In order to ensure a virgin state (RHO), the specimens were tested just after curing. The two other specimens were conditioned at $70 \%$ relative humidity at $60^{\circ}$ Celsius for fifteen days. This conditioning process was based on the work of Broud in that it predicted a complete saturation at $70 \%$ humidity of $2-\mathrm{mm}$ thick PA66 composite plates under the conditions established [27]. However, it is important to say that this conditioning does not ensure $70 \%$ RH saturation either of the adhesive joint, or the interface. Figure 12 presents the experimental results for the two types of specimens described before. It can be observed that the presence of humidity leads to an early non-linear threshold at a lower failure load (about $-16 \%$ ) compared to the virgin state. It is worth noting that the curves are superposed at the linear part at the beginning of the test. For the assemblies with $0 \%$ humidity, the fracture was adhesive. On the contrary, the assemblies with $70 \%$ humidity presented a partial cohesive fracture. This phenomenon suggests that the strength of the adhesive is severely affected by the presence of humidity and not the composite or the interface.

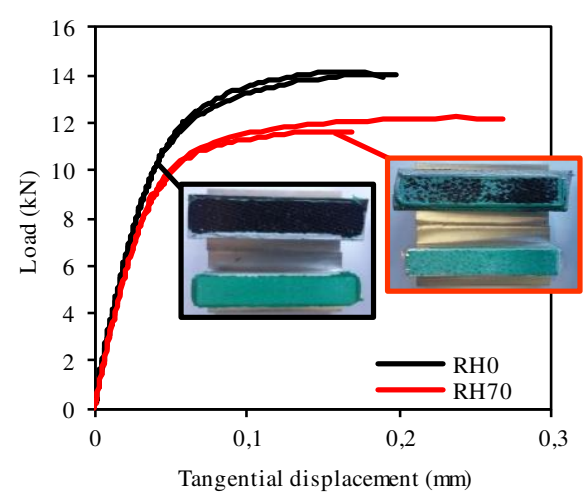

(a)

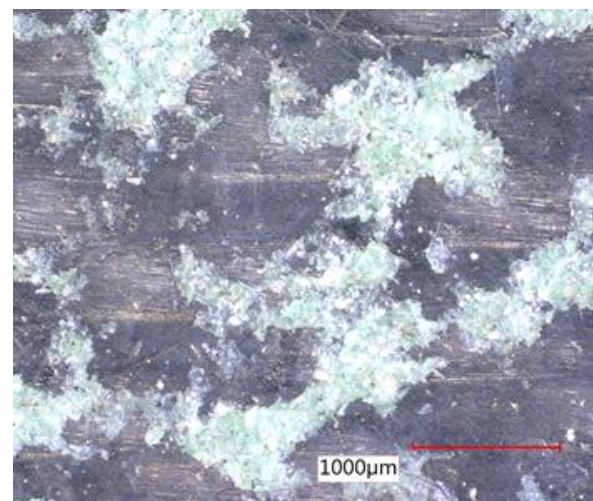

(b)

Figure 12: Influence of the humidity over the BM1822/PA66 assemblies under shear monotonic Arcan test. Loaddisplacement response of RH0 and RH70 specimens (a) and Keyence digital microscopic image of the fracture surface of the RH70 specimens (b). 


\subsection{Bonded aluminium/metal assemblies}

The use of adhesives to join metals could be an optimal alternative to the classic solutions such as bolting, riveting, welding, etc. This technique provides a high strength/lightness performance while allowing complex geometry pieces to be joined. This is why this section is consecrated to the study of aluminium/metal assemblies. The metal plates were made of aluminium 5182 and Steel 22MnB5. In the first case, the metal plates followed a degreasing procedure of the bonded surfaces in order to remove all possible pollutants and ensure optimal adhesion. However, according to automotive requirements where the materials are exposed to greasy environments, it is important to determine the influence of grease on the strength of the bonded assembly. Consequently, some metal plates followed a standardised degreasing-greasing process employed in the automotive industry. The basic bonding procedure presented in Section 2.2 was not respected and the greased metal plates were bonded directly to the substrates of the specimen without acetone cleaning.

Figure 13 shows the comparison between the failure envelopes for greasy and non-greasy assemblies. The failure modes are also given. The results show that the SP498/Steel22MnB5 specimens were strongly affected by the presence of grease on the bonded surface. Indeed, the failure load decreased by about $25 \%$ when the surface was greased. However, since the failure occurred at the substrate/adhesive interface, it cannot be possible to conclude if the SP498/22MnB5 assembly was affected, or not, by the presence of grease. The fracture presented in this case was approximately $60 \%$ cohesive and $40 \%$ adhesive. 
For all the other assemblies, the failure was always cohesive and the strength was close to the adhesive strength. It means that these assemblies were independent of the presence of grease, ensuring a good adhesion between the adhesive and the metal plate.

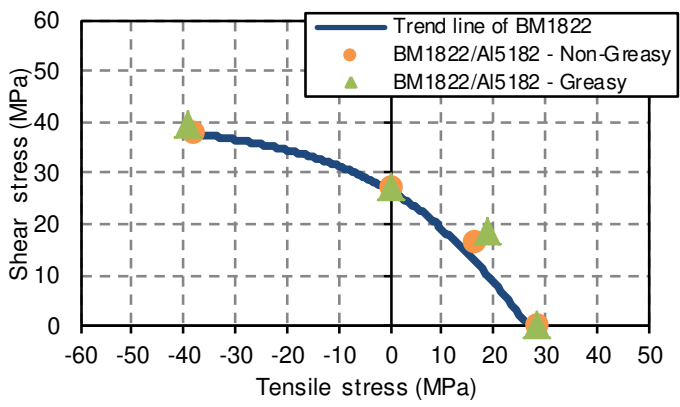

Failure envelope

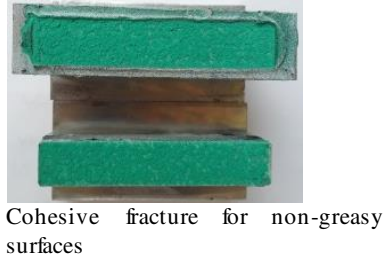

a) BM1822/AL5182

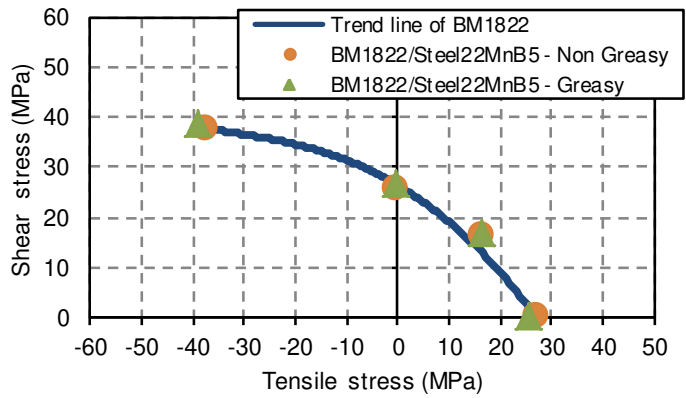

Failure envelope

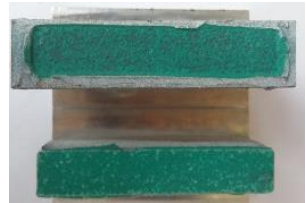

Cohesive fracture for non-greasy surfaces

c) BM1822/Steel22MnB5

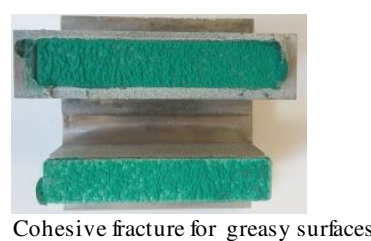

Cohesive fracture for greasy surfaces

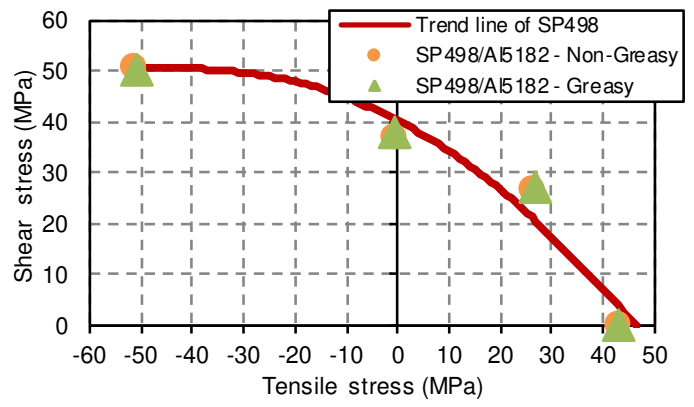

Failure envelope

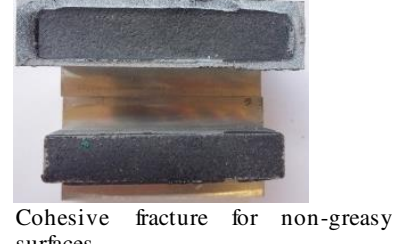

surfaces

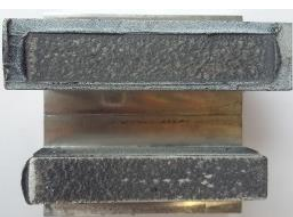

Cohesive fracture for greasy surfaces

b) SP498/AL5182

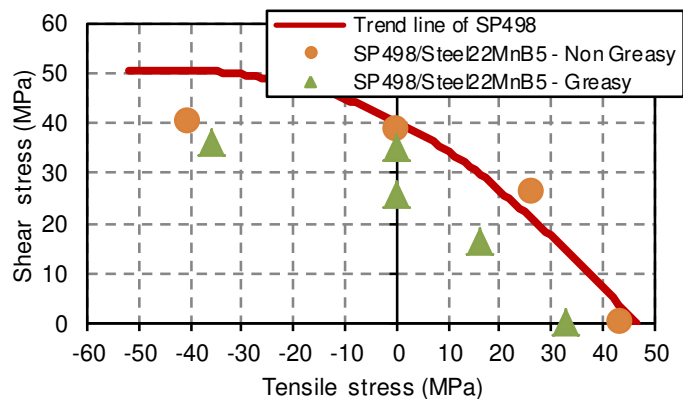

Failure envelope
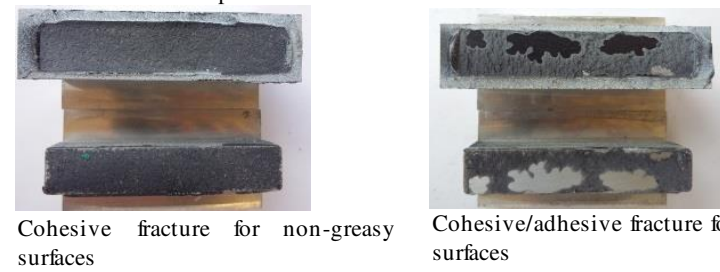

Cohesive/adhesive fracture for greasy surfaces

d) SP498/Steel22MnB5

Figure 13: Failure envelope for adhesively-bonded aluminium/metal as semblies and influence of greasy surfaces . 


\section{CONCLUSIONS}

The use of adhesively bonded assemblies in automotive applications requires that manufacturers prove that failure in every assembly and for every possible type of loading always remains cohesive.

To this end, it is necessary to demonstrate the cohesive nature of the failure (i) in areas with a low-gradient of stress and (ii) in areas with high stress concentrations, for example, close to the edges. The research presented in this paper concentrated on the first case. The use of the modified Arcan device with specimens reducing the edge effects permitted the type of failure of several assemblies and for different configurations to be studied. The influence of some parameters on the strength of the assemblies has also been analysed.

The methodology followed in this study enabled the behaviour of adhesively-bonded assemblies to be analysed. The advantages of the modified Arcan device in characterising the strength of bonded assemblies were also demonstrated. A wide range of different assemblies have been evaluated and some of their advantages/disadvantages have been discussed.

The application of manual sandblasting seems to improve the performance of aluminium/composite assemblies. The explanation could be the better adhesion between the adhesive and the fibre of the composite. The failure mode could also change. This technique could be used to join "incompatible" materials such as thermoplastic composites and epoxy adhesives to improve the adhesion between them.

For adhesively-bonded assemblies it is crucial to analyse not only the optimal state of the assembly but also the influence of some crucial parameters that could lead to an early failure of 
the assembly. The choice of which assembly to use depends on the application and on the user requirements.

The influence of the presence of grease in adhesively-bonded aluminium/metal assemblies depends on the nature of the adhesive and metals used. In particular, the use of the same adhesive tested to join a particular metal material does not also ensure good adhesion with another metal material.

Thanks to the experimental results presented in this study, a set of bonded assemblies leading to cohesive failure has been determined, that is, with good interface strength: BM1822/Prepreg, SP498/Prepreg, BM1822/PA66 with manual sandblasting, BM1822/AL5182, SP498/AL5182 and BM1822/Steel22MnB5. However, additional lap-shear tests were also performed for these assemblies and for some of them the failure was adhesive (BM1822/Stee22MnB5). This aspect underlines that the failure can be affected by some other parameters that are inherent to the type of test such as the presence of edge effects or the plasticity of the substrates. Therefore, the study of bonded assemblies by means of the modified Arcan device with specimens reducing the edge effects is not enough to validate cohesive failures under any circumstance. Similarly, the simple use of lap-shear tests may not be a good solution either; this is because this type of test is not representative of the possible types of loading presented during the service life of the automobile (mixed tensile/compression/shear loadings). Therefore, it is necessary to propose a test permitting the joint to be subject to a wide range of mixed loadings enabling high gradient stress zones at the adhesive/adherend interface to be located. In order to achieve this goal, the use of the modified Arcan specimens without "beaks" or the use of scarf joints can be considered to be suitable solutions in order to introduce some edge effects localising the stresses at the interface, while enabling the adhesive joint to be subjected to multi-axial loadings as proposed in [32]. 


\section{Acknowledgements}

The authors acknowledge the ADEME agency for financially supporting the study. The partners of the Fastlite project are also acknowledged for all the valuable discussions. The authors wish to express their gratitude to Georgios Stamoulis for his relevant contribution to this paper.

\section{REFERENCES}

[1] T. Renault, 'Les matériaux composites dans l'automobile', Mécanique Ind., vol. 2, no. 3, pp. 211-218, May 2001.

[2] X. Jiang, M. H. Kolstein, and F. S. K. Bijlaard, 'Experimental and numerical study on mechanical behavior of an adhesively-bonded joint of FRP-steel composite bridge under shear loading', Compos. Struct., vol. 108, pp. 387-399, Feb. 2014.

[3] P. P. Camanho and F. L. Matthews, 'Stress analysis and strength prediction of mechanically fastened joints in FRP: a review', Compos. Part Appl. Sci. Manuf., vol. 28, no. 6, pp. 529547, 1997.

[4] E. W. Godwin and F. L. Matthews, 'A review of the strength of joints in fibre-reinforced plastics: Part 1. Mechanically fastened joints', Composites, vol. 11, no. 3, pp. 155-160, Jul. 1980.

[5] J. Y. Cognard, L. Sohier, and P. Davies, 'A modified Arcan test to analyze the behavior of composites and their assemblies under out-of-plane loadings', Compos. Part Appl. Sci. Manuf., vol. 42, no. 1, pp. 111-121, Jan. 2011.

[6] L. F M da Silva and R. D Adams, 'Techniques to reduce the peel stresses in adhesive joints with composites', Int. J. Adhes. Adhes., vol. 27, no. 3, pp. 227-235, Apr. 2007.

[7] D. Morin, G. Haugou, B. Bennani, and F. Lauro, 'Identification of a new failure criterion for toughened epoxy adhesive', Eng. Fract. Mech., vol. 77, no. 17, pp. 3481-3500, Nov. 2010.

[8] D. M. Antunes, V. Infante, and A. Reis, 'Experimental Adhesive Failure Criteria for Analys is of Aerospace Structures', Procedia Eng., vol. 114, pp. 416-421, 2015.

[9] ASTM D5656-04, 'Standard Test Method for Thick-Adherend Metal Lap-Shear Joints for Determination of the Stress-Strain Behavior of Adhesives in Shear by Tension Loading'. ASTM International, West Conshohocken, PA, 2004.

[10] ASTM D1002-05, 'Standard Test Method for Apparent Shear Strength of Single-Lap-Joint Adhesively Bonded Metal Specimens by Tension Loading (Metal-to-Metal)'. ASTM International, West Conshohocken, PA, 2005.

[11] L. Liao, C. Huang, and T. Sawa, 'Effect of adhesive thickness, adhesive type and scarf angle on the mechanical properties of scarf adhesive joints', Int. J. Solids Struct., vol. 50, no. 25-26, pp. 4333-4340, Dec. 2013.

[12] J. P. M. Gonçalves, M. F. S. F. de Moura, and P. M. S. T. de Castro, 'A three-dimensional finite element model for stress analysis of adhesive joints', Int. J. Adhes. Adhes., vol. 22, no. 5, pp. 357-365, 2002. 
[13] J. Y. Cognard, P. Davies, B. Gineste, and L. Sohier, 'Development of an improved adhesive test method for composite assembly design', Compos. Sci. Technol., vol. 65, no. 3-4, pp. 359-368, Mar. 2005.

[14] M. Arcan, Z. Hashin, and A. Voloshin, 'A method to produce uniform plane-stress states with applications to fiber-reinforced materials', Exp. Mech., vol. 18, no. 4, pp. 141-146, Apr. 1978.

[15] G. Stamoulis, N. Carrere, J.-Y. Cognard, P. Davies, and C. Badulescu, 'Investigating the fracture behavior of adhesively bonded metallic joints using the Arcan fixture', Int. J. Adhes. Adhes., vol. 66, pp. 147-159, Apr. 2016.

[16] P. Jousset and M. Rachik, 'Implementation, identification and validation of an elastoplastic-damage model for the finite element simulation of structural bonded joints', Int. J. Adhes. Adhes., vol. 50, pp. 107-118, Apr. 2014.

[17] L. Dufour, B. Bourel, F. Lauro, G. Haugou, and N. Leconte, 'A viscoelastic-viscoplastic model with non associative plasticity for the modelling of bonded joints at high strain rates', Int. J. Adhes. Adhes., vol. 70, pp. 304-314, Oct. 2016.

[18] J. Y. Cognard, 'Numerical analysis of edge effects in adhesively-bonded assemblies application to the determination of the adhesive behaviour', Comput. Struct., vol. 86, no. 17-18, pp. 1704-1717, Sep. 2008.

[19] D. Thevenet, R. Créac'hcadec, L. Sohier, and J. Y. Cognard, 'Experimental analysis of the behavior of adhesively bonded joints under tensile/compression-shear cyclic loadings', Int. J. Adhes. Adhes., vol. 44, pp. 15-25, Jul. 2013.

[20] C. Badulescu, C. Germain, J.-Y. Cognard, and N. Carrere, 'Characterization and modelling of the viscous behaviour of adhesives using the modified Arcan device', J. Adhes. Sci. Technol., vol. 29, no. 5, pp. 443-461, Mar. 2015.

[21] C. Badulescu, J. Y. Cognard, R. Créac'hcadec, and P. Vedrine, 'Analys is of the low temperature-dependent behaviour of a ductile adhesive under monotonic tensile/compression-shear loads', Int. J. Adhes. Adhes., vol. 36, pp. 56-64, Jul. 2012.

[22] L. Alfonso, A. Uguen, C. Badulescu, J.-Y. Cognard, T. Bonnemains, E. Lolive, and N. Carrere, 'Determination of the 3D failure envelope of a composite based on a modified Arcan test device', Compos. Struct., vol. 131, pp. 585-593, Nov. 2015.

[23] L. Sohier, J. Y. Cognard, and P. Davies, 'Analysis of the mechanical behaviour of adhesively bonded assemblies of composites under tensile-shear out-of-plane loads', Compos. Part Appl. Sci. Manuf., vol. 53, pp. 65-74, Oct. 2013.

[24] GOM, Aramis ${ }^{\circledR}$ software version 6.3.1. 2011.

[25] C. D.-14 ASTM 5573, 'Standard Practice for classifying failure modes in fiber-reinforcedplastic (FRP) joints', Annual Book of ASTM Standards, United States, Apr-1999.

[26] Jean-Yves Cognard, M. Bourgeois, Romain Créac'Hcadec, and Laurent Sohier, 'Comparative study of the results of various experimental tests used for the analysis of the mechanical behaviour of an adhesive in a bonded joint', J. Adhes. Sci. Technol. Taylor Francis, vol. 25, pp. 2857-2879, 2011.

[27] J. Y. Cognard, R. Créac'hcadec, L. Sohier, and D. Leguillon, 'Influence of adhesive thickness on the behaviour of bonded assemblies under shear loadings using a modified TAST fixture', Int. J. Adhes. Adhes., vol. 30, no. 5, pp. 257-266, Jul. 2010.

[28] P. Davies, L. Sohier, J.-Y. Cognard, A. Bourmaud, D. Choqueuse, E. Rinnert, and R. Créac'hcadec, 'Influence of adhesive bond line thickness on joint strength', Int. J. Adhes. Adhes., vol. 29, no. 7, pp. 724-736, Oct. 2009. 
[29] D. M. Brewis, J. Comyn, and R. J. A. Shalash, 'The effect of moisture and temperature on the properties of an epoxide-polyamide adhesive in relation to its performance in single lap joints', Int. J. Adhes. Adhes., vol. 2, no. 4, pp. 215-222, Oct. 1982.

[30] J. Chaichanawong, C. Thongchuea, and S. Areerat, 'Effect of moisture on the mechanical properties of glass fiber reinforced polyamide composites', Adv. Powder Technol., 2016.

[31] M. Broudin, P. Y. Le Gac, V. Le Saux, C. Champy, G. Robert, P. Charrier, and Y. Marco, 'Water diffusivity in PA66: Experimental characterization and modeling based on free volume theory', Eur. Polym. J., vol. 67, pp. 326-334, Jun. 2015.

[32] N. Carrere, C. Badulescu, J.-Y. Cognard, and D. Leguillon, '3D models of specimens with a scarf joint to test the adhesive and cohesive multi-axial behavior of adhesives', Int. J. Adhes. Adhes., vol. 62, pp. 154-164, Oct. 2015. 